Article

\title{
Smart Card Data Mining to Analyze Mobility Patterns in Suburban Areas
}

\author{
Cristina Pronello $1,2, * \mathbb{C}$, Davide Longhi ${ }^{2}$ and Jean-Baptiste Gaborieau ${ }^{2}$ \\ 1 Département Génie des Systèmes Urbains (GSU) \& EA 7284 AVENUES, Sorbonne Universités-Université \\ de Technologie de Compiègne, 60200 Compiègne, France \\ 2 Dipartimento Interateneo di Scienze, Progetto e Politiche del Territorio, Politecnico di Torino, 10125 Torino, \\ Italy; davide.longhi@polito.it (D.L.); jeanbaptiste.gaborieau@polito.it (J.-B.G.) \\ * Correspondence: cristina.pronello@utc.fr; Tel.: +33-(0)3-44234406
}

Received: 26 July 2018; Accepted: 27 September 2018; Published: 29 September 2018

check for updates

\begin{abstract}
This paper aims to define an algorithm capable of building the origin-destination matrix from check-in data collected in the extra-urban area of Torino, Italy, where thousands of people commute every day, using smart cards to validate their travel documents while boarding. To this end, the methodological approach relied on a survey over three months to record smart-card validations. Peak and off-peak periods have been defined according to validation frequency. Then, the origin-destination matrix has been estimated using the time interval between two validations to outline the different legs of the journey. Finally, transport demand has been matched with existing bus services, showing which areas were not adequately covered by public transport. The results of this research could assist public transport operators and local authorities in the design of a more suitable transport supply and mobility services in accordance with user needs. Indeed, tailoring public transport to user needs attracts both more customers and latent demand, reducing reliance on cars and making transport more sustainable.
\end{abstract}

Keywords: public transport; sustainable transport; AFCS (automated fare collection systems); smart-card; algorithm; origin-destination estimation; transport demand and supply

\section{Introduction}

To achieve a sustainable transport system requires understanding transport demand, which is a key element in transport planning. However, it is also a challenging task due to the high costs of travel surveys. The new technologies developed for intelligent transport systems (ITS) increasingly facilitate data collection, and, to this end, automated fare collection (AFC) systems can play a key role. Although AFC systems were introduced almost fifty years ago in Germany, their usage in the transport sector has increased enormously during recent years [1,2]. Fraud detection, the reduction of boarding times, and management of transport operators' revenue were among the main reasons leading transport companies to convert their traditional ticketing systems to more up-to-date AFC systems [3-5]. Data coming from AFC systems are also useful for analyzing passenger mobility patterns [6-8], as well as spatiotemporal information on boarding and alighting [9-11].

A further advantage of AFC systems is provided by the possibility of extending ticketing systems to different transport operators and other modes of transport, making multimodal trips possible and simpler.

Furthermore, more recently, validation data have also been used by transport authorities and transport operators to monitor load factors and analyze users' travel behavior and trips [1,12]. Therefore, data obtained from validations can be seen as a valuable complement to travel surveys to better design a transport supply based on user needs [13,14]. 
State-of-the-art systems which focus on the estimation of origin-destination matrices from smart-card validations can be differentiated according to the type of validation. In some transport systems both check-in and check-out are mandatory while, in other cases, passengers have to validate their transport titles only when they board. Only a few cases provide an entry-exit system, like those of south-east Queensland in Australia [7] and Seoul [15], while the majority of cases concern entry-only systems [1], such as, for example, those of New York [16], Chicago [8], Santiago [17], and Guangzhou [18]. Thus, many researchers have focused on entry-only systems, trying to define the destination from the origin [8,16,19-23]. Nevertheless, additional effort is needed to estimate destinations through check-in validations because the adopted methods are diverse and matching rates differ [24].

Models used to infer destinations differ according to the validation system; trip-chaining models are used mostly where entry-only systems are present, and validated where entry-exit systems are used. Probability models and deep learning models have begun to be used more recently. Tian et al. [24] review the methods and models to infer destination from origins recorded by smart cards and they make a comparison, showing the pros and cons of the above methods (Table 1).

Table 1. Pros and cons of the models estimating destinations from origin information.

\begin{tabular}{|c|c|c|}
\hline Destination Estimation Model & Advantage & Disadvantage \\
\hline Trip Chaining Model & $\begin{array}{l}\text { - } \quad \text { Only need smart card data } \\
\text { - } \quad \text { The algorithm is relatively simple } \\
\text { - Can infer light station of } \\
\text { each passenger }\end{array}$ & $\begin{array}{l}\text { Difficult to validate the } \\
\text { model with sufficient data }\end{array}$ \\
\hline Probability Model & $\begin{array}{l}\text { considerations are } \\
\text { more comprehensive }\end{array}$ & $\begin{array}{l}\text { - Only infer total on-off } \\
\text { passenger number without } \\
\text { individual alight information }\end{array}$ \\
\hline Deep learning model & $\begin{array}{l}\text { - The considerations are } \\
\text { very comprehensive } \\
\text { - Can infer the alight station of } \\
\text { each passenger } \\
\text { The model can be validated by } \\
\text { numerous travel data }\end{array}$ & $\begin{array}{l}\text { - Need abundant data } \\
\text { - Only appropriate for } \\
\text { entry-exit system } \\
\text { - The algorithm is } \\
\text { more complex }\end{array}$ \\
\hline
\end{tabular}

Source: [24].

This paper aims to define the mobility patterns of the users of public transport in the rural areas of the province of Torino (situated in north-west Italy and including more than 300 municipalities), thanks to smart card data. While much research work is focused on urban areas [25-27], our paper focuses on long-distance trips, implying a longer leg outside the city followed by a transfer in a city hub. This aspect challenges the methods described above, which are mainly applied in urban environments, as well as the adopted hypotheses that need to be verified in different contexts. Furthermore, the diversity of the available data coming from AFC systems is a constraint in the selection of the most appropriate method. To this end, the Extra.To company, which supplies public transport in the aforementioned area, asked us to determine the destinations of users from their AFC system providing entry-only validations. Thus, selection of the most appropriate methodology to be used is another key aspect of this paper.

The ultimate aim of the company, given knowledge of the origins/destinations of their users, was to check if the public transport network in such an area truly fulfils the users' needs, and if it is efficiently designed, or if a reorganization could lead to an increase in the quality and attractiveness of its service and, thus, its ridership. 
The next section focuses on the methodology, describing the survey, the model definition, and the data analysis design. Finally, results are discussed, conclusions made, and suggestions to policy makers are put forward.

\section{Materials and Methods}

The regional transport authority and the Piedmont Region assert that BIP (Biglietto Integrato Piemonte: Integrated Ticket Piedmont) can play a key role in the certification of the quality and the quantity of transport demand [28]; thus, since 2017, check-in validation is mandatory on all urban and provincial transport services. The smart card validation data are collected thanks to the automatic vehicle monitoring (AVM) system, a contactless validator paired with a GPRS-GNSS-WiFi antenna (GPRS: General Packet Radio Service. GNSS: global navigation satellite system).

The methodological approach has been set up to define an algorithm capable of building the origin-destination matrix from the entry-only data collected in the area of Torino province (Italy), where thousands of people commute each day using smart cards to validate their travel documents while boarding (Figure 1). This research focuses on validations occurring between 22 February and 8 May 2016, on the buses of the Extra.To consortium that adopted mandatory validation prior to it being introduced as a legal requirement. From 2010, Extra.To has been the only transport operator in the area of Torino province; the group includes the seventeen main transport operators, which operate 212 bus lines with more than 650 vehicles.

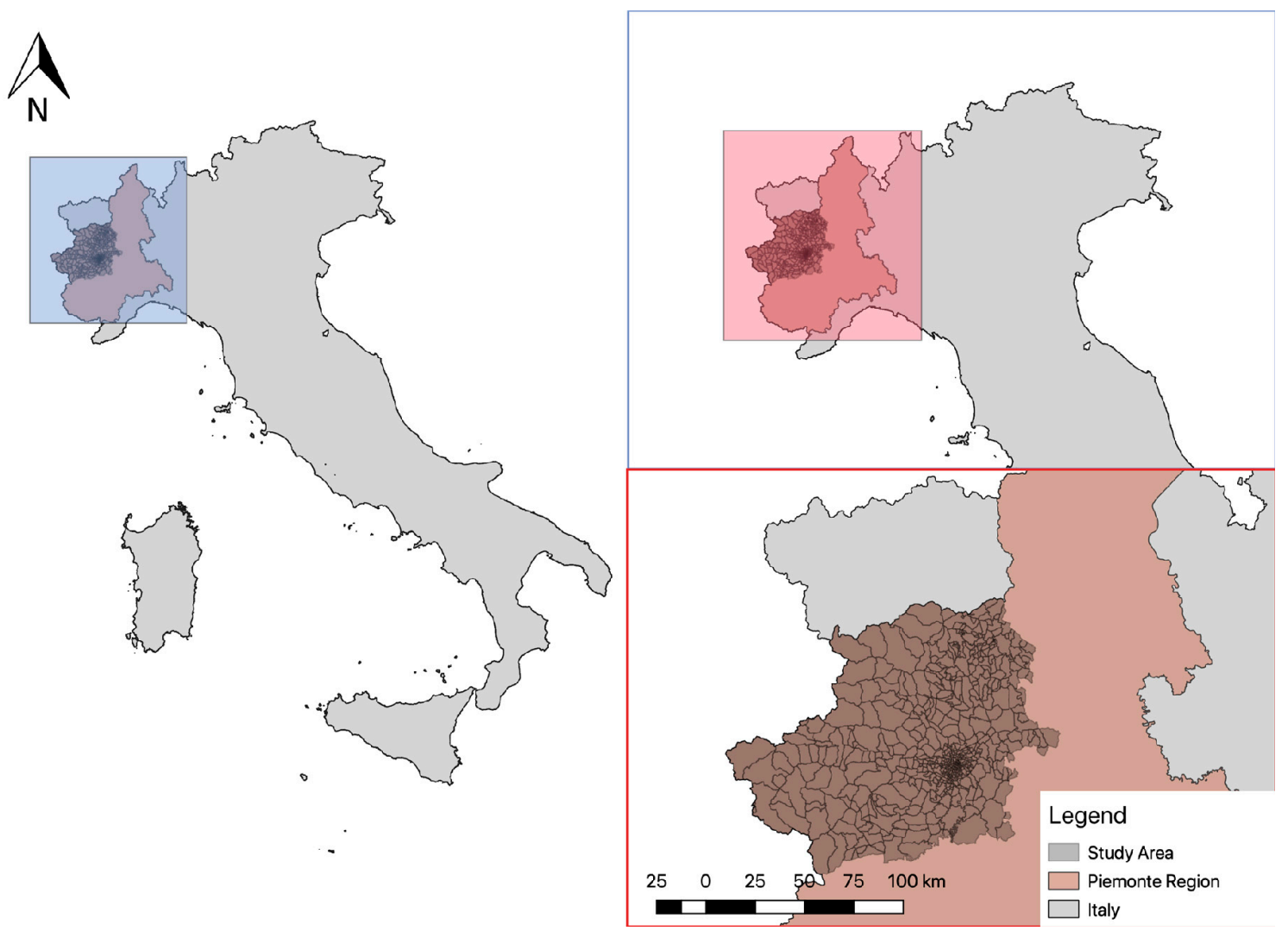

Figure 1. Definition of the study area.

The methodology involves five steps: (1) zoning of the study area; (2) extraction and analysis of the validation data; (3) selection and definition of the model to infer destinations; (4) definition of transport supply and demand; and (5) analysis and visual display of transport supply and demand, and of their interaction. 
The definition of traffic zones within the study area was constrained by the current zoning used by the transport authority in the metropolitan area of Torino, as shown in Figure 2; there are 261 zones, comprising 166 in Torino and 95 in the metropolitan area [29]. Outside of the metropolitan area, a further 281 zones have been defined, corresponding to the administrative territory (281 municipalities).

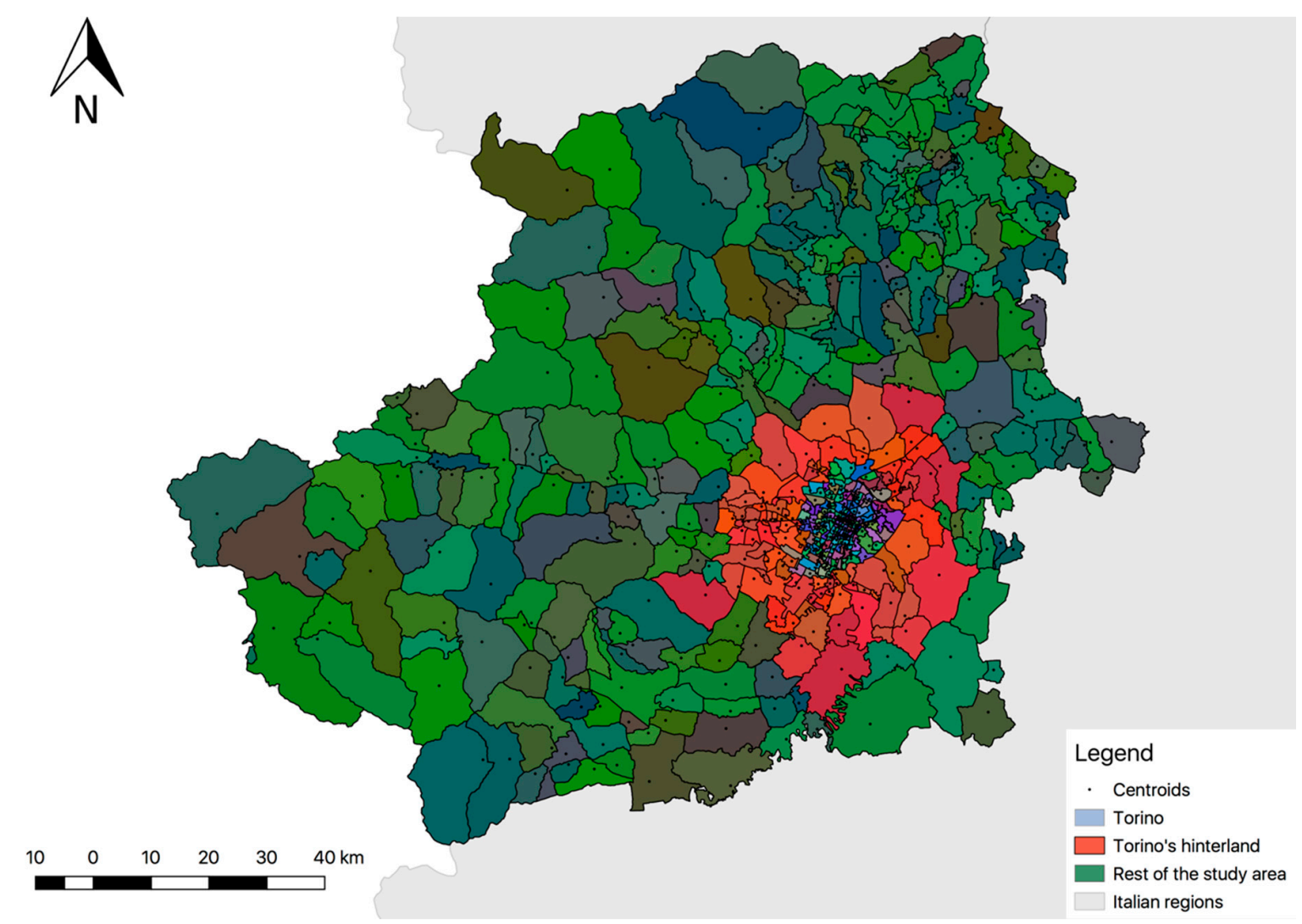

Figure 2. Definition of traffic zones in the study area.

The centroids of the zones of the metropolitan area correspond to the position defined by the transport authority, while for the Torino province the city center has been used for each zone (municipality). In Figure 3, a detail of the location of centroids (white points) in the zones outside the metropolitan area is shown.

Since the area of Torino province counts more than 9500 bus stops within $6830 \mathrm{~km}^{2}$, the stops located in the same zone were aggregated and assigned to the centroids in order to facilitate the analysis and the visualization of the desired lines. Table 2 shows the number of stops among the different zones.

After defining zoning of the study area, the validation data were extracted from the control center through the Business Object of SAP [30]. To guarantee user privacy, the IDs of smart cards were encrypted and all sensitive information removed, in accordance with Italian privacy policy [31]. Next, a database was established, including both the information contained in the report listing all the validations and data related to the service. Notably, information included: Smart Card ID, Date of birth, Age, Age Range, Gender, Company ID, Company Name, Company ID, Seat number, Bus license plate, Bus Line ID, Stop ID, Zone ID, Stop Latitude, Stop Longitude, Validation day, Name of day, Validation time, Validation time slot, Type of journey, System error related to data collection, Origin Stop ID, Destination Stop ID, Origin Zone ID, and Destination Zone ID. 


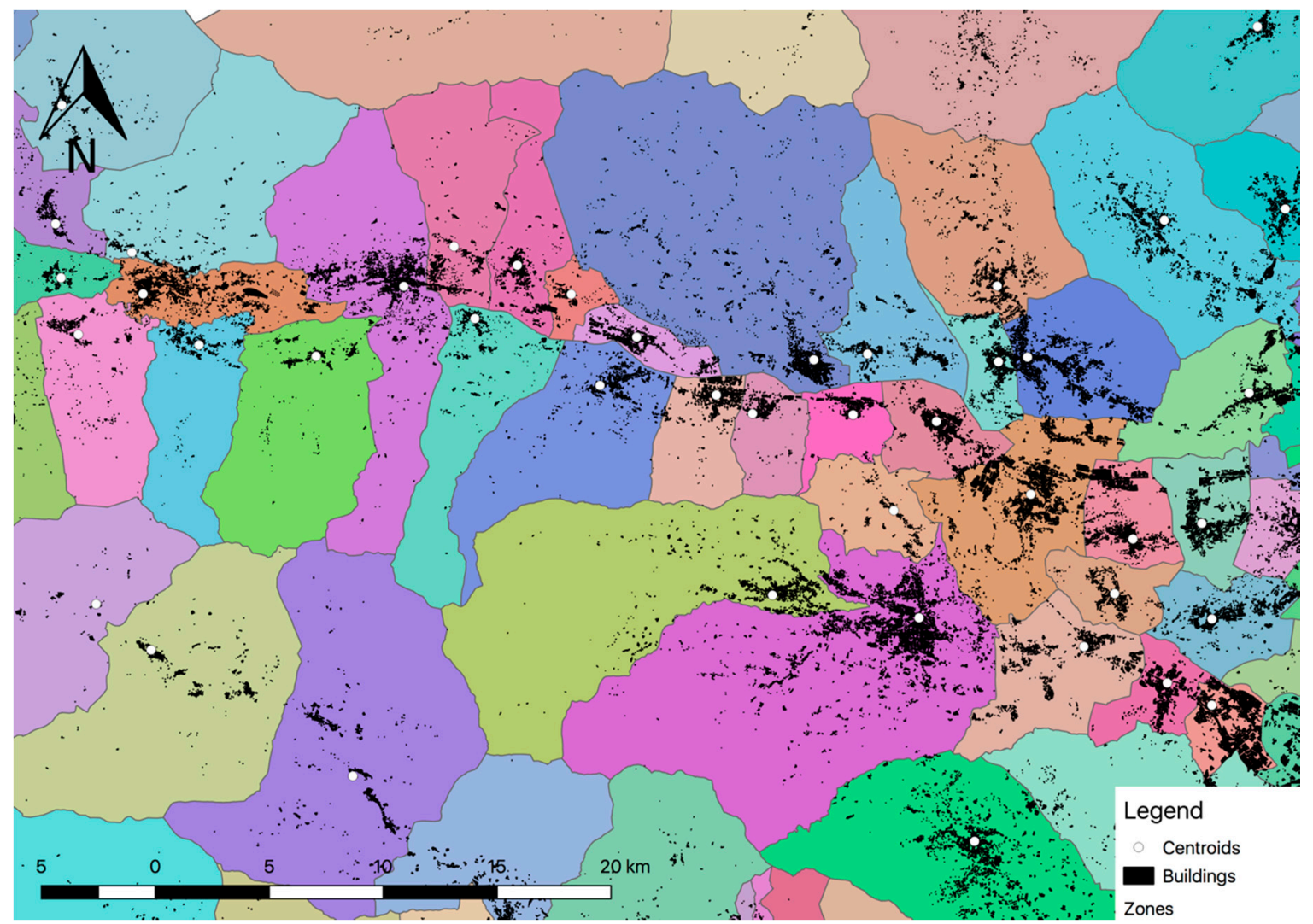

Figure 3. Location of centroids (white points) in the zones outside the metropolitan area.

Table 2. Zoning of the study area.

\begin{tabular}{cccc}
\hline & Surface $\mathbf{( k m}^{2} \mathbf{)}$ & Number of Stops & Number of Zones \\
\hline Torino & 130.17 & 2606 & 166 \\
Torino's hinterland & 726.58 & 2170 & 95 \\
Rest of study area & 5954.17 & 4800 & 281 \\
\hline
\end{tabular}

Finally, the evaluation of the data quality was carried out. To this end, validations collected during the research period were assessed to exclude those not containing information related to the bus line (bus line ID); notably, the most frequent errors observed were "Bus line ID =0" and "No AVM". At the same time, validations were classified as a function of fare subscription to understand the percentage of commuters and occasional passengers. The distribution of the number of validations during the daytime was analyzed to define the main peak and off-peak hours for both weekdays and weekends.

\subsection{Model Selection and Definition}

The availability of data influenced the choice of the most appropriate model to infer destinations. Indeed, our data refer to entry-only validations; we did not have any data related to origin-destination information from buses to train the model and we did not have any information about travel distances of the passengers. Given the above situation, the trip-chaining model revealed itself as the model which best fit our data, following the hypotheses of Barry et al. [16], and improved by Zhao et al. [8]. Figure 4 shows the schematic flow chart of the data-set and of the processing to define a procedure to generate linked passenger trips — origin and destination-for a given day. More precisely, the left of the flow chart depicts the available data related to the user characteristics and to the service (operator; line, bus and stop ID; time of validation; and, fare). Algorithm components are shown at the right 
of Figure 4: time period and type of trip, as well as age ranges to characterize the user and the related fare. The details of the data processing are given below.

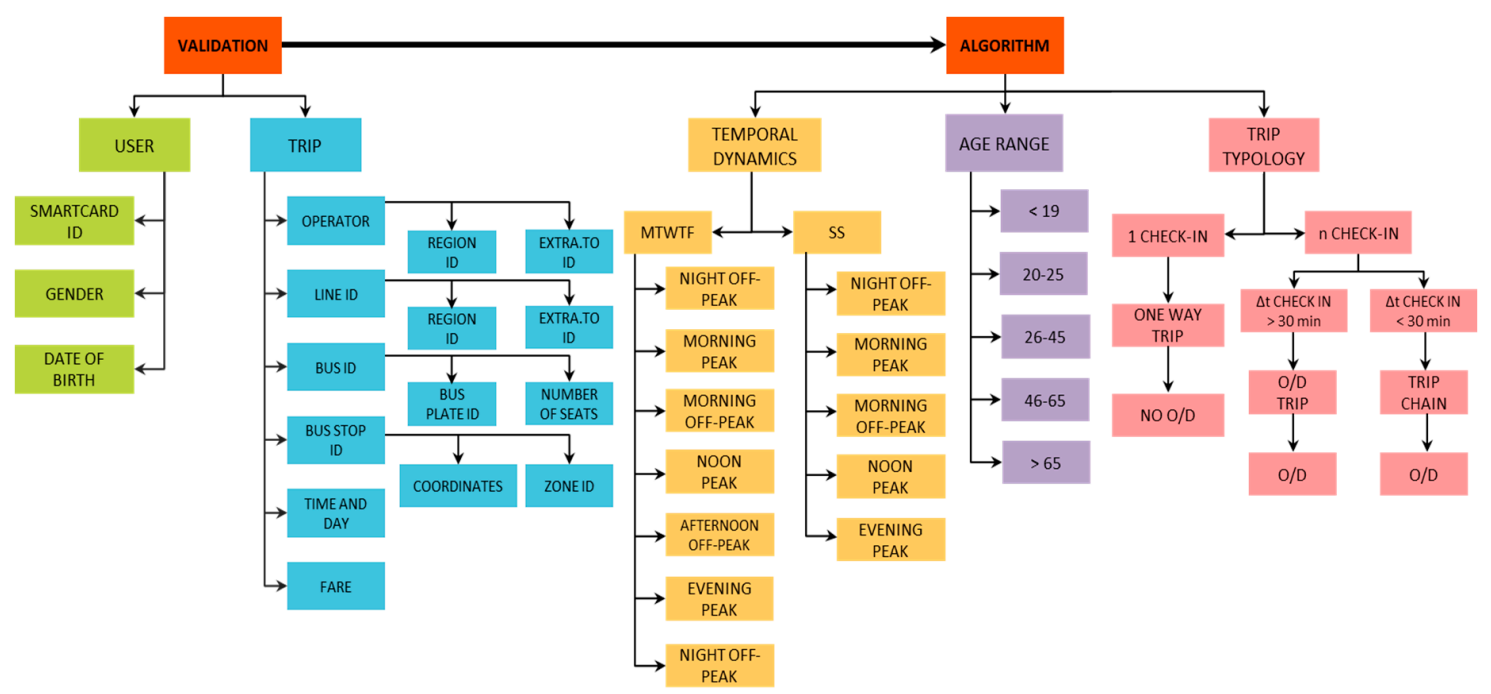

Figure 4. Data processing.

The trip chain is formed by a series of linked trips having one origin and one destination related to a single activity. Each trip leg has, in turn, an origin and a destination aimed at connecting the legs of the whole trip chain. The demand analysis implied distinguishing the validations according to the travel typology made by the user. The time basis of the analysis is $24 \mathrm{~h} \mathrm{(00:00-23:99)}$ and the time between two validations is contained in this interval.

In Table 3, validations of two cards are shown with the information related to the time interval between two check-ins ( $\Delta \mathrm{t}$ check-in). Such a time interval allowed us to understand if the travel associated with a specific validation was for a trip or a trip-chain (i.e., if the time interval was too small).

Table 3. Example of the calculation of the minimum difference between two check-ins.

\begin{tabular}{ccccc}
\hline CARD_ID & DATE_VALID. & TIME_VALID. & $\begin{array}{c}\text { TIME_MIN_VALID. } \\
\text { (min) }\end{array}$ & $\begin{array}{c}\Delta t \text { CHECK-IN } \\
\text { (min) }\end{array}$ \\
\hline 123456789 & 21 March 2016 & $05: 56: 24$ & 356 & 1 st CHECK-IN \\
123456789 & 21 March 2016 & $06: 32: 26$ & 392 & 36 \\
123456789 & 21 March 2016 & $19: 02: 54$ & 1142 & 750 \\
123456789 & 21 March 2016 & $19: 24: 07$ & 1167 & 25 \\
\hline 456789123 & 21 March 2016 & $04: 55: 17$ & 295 & 1st CHECK-IN \\
456789123 & 21 March 2016 & $14: 30: 31$ & 870 & 575 \\
\hline
\end{tabular}

Note: CARD_ID: unique smartcard identity number; DATE_VALID: smartcard validation date; TIME_VALID: smartcard validation time; TIME_MIN_VALID: smart validation time in minutes from 00:00.

At the same time, the minimum time difference to consider that two check-ins were a leg of a trip-chain was defined via analysis of its density function (Figure 5), showing that the average time between two check-ins is $384 \mathrm{~min}$ (about $6.5 \mathrm{~h}$ ). This value is close to the duration of a school day and, in fact, most users are students. 


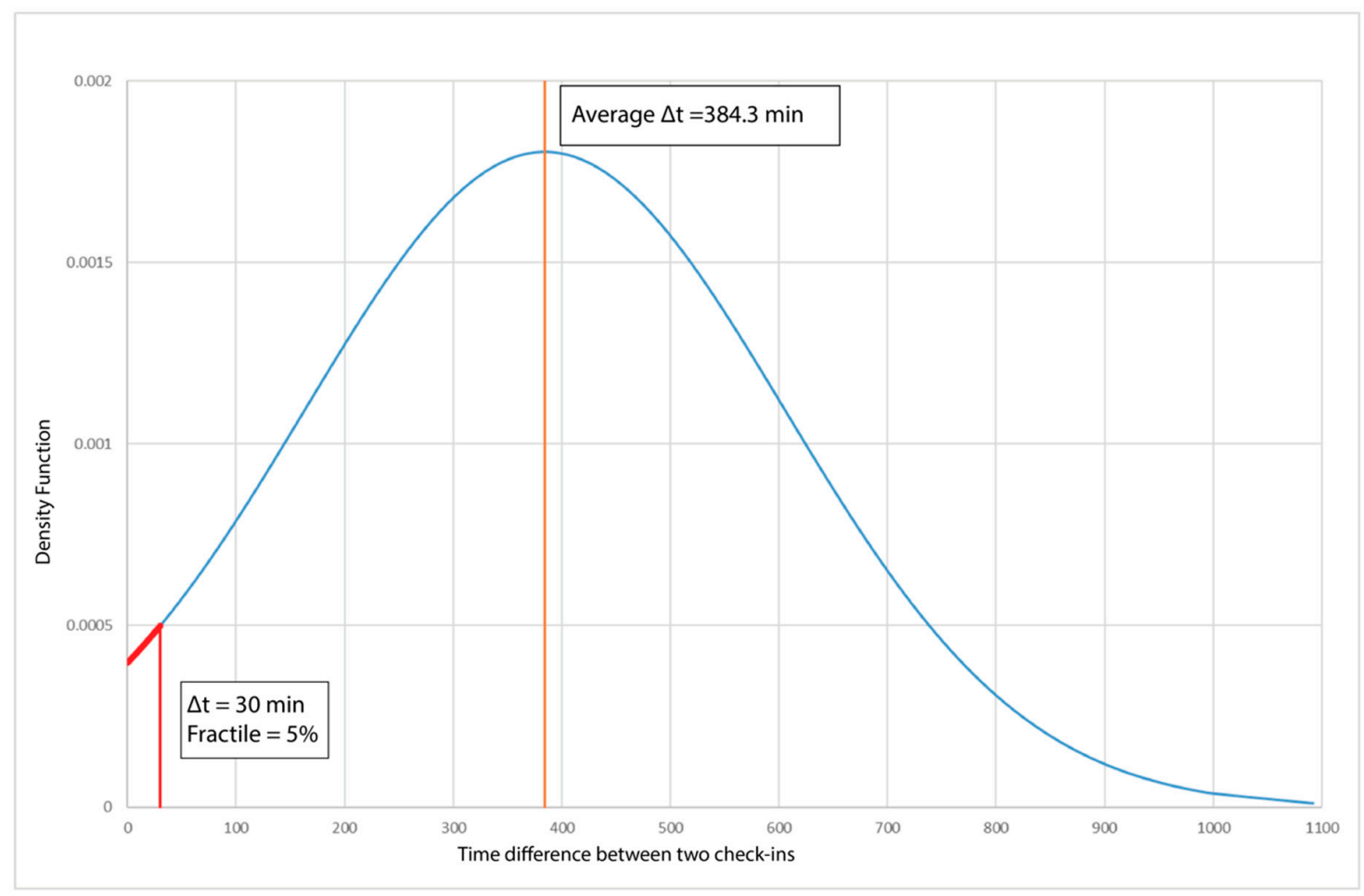

Figure 5. Density function of the time difference between two check-ins.

To confirm the hypothesis of the minimum time difference between two check-ins, check-in time was compared with the travel times between pairs of stops. This comparison allowed us to distinguish between waiting time and travel time. The network analysis tool ArcMap [32] was used, allowing average travel times (considering the average speed on the routes) between origins and destinations to be calculated. The calculation was carried out for the Extra.To network, where stops represented nodes, and links, for all the bus lines, were represented by the geometric lines between two stops. The network was built in three steps: (a) construction of the graph; (b) addition of the information on origins and destinations related to the stops; and (c) construction of the origin-destination matrix using network analysis, including all the information related to the travel time and distance between each pair of stops. The matrix has the format shown in Table 4. Finally, the travel time between two stops was compared with the time difference between two validations of two consecutive stops. The trips with a $\Delta \mathrm{t}$ check-in (time interval between two check-ins) of less than 30 min were selected; we observed that the time obtained from network analysis was consistent with $\Delta t$ check-in, confirming the reliability of the calculation.

Thus, 30 min was considered the maximum time interval between two consecutive validations forming a leg, corresponding to the $5 \%$ fractile of the probability density function shown in Figure 5 . Thus, two validations occurring with a time interval longer than $30 \mathrm{~min}$ correspond to two trips separated by an activity in the middle.

Zhao et al. [8], instead, use a maximum time interval of $40 \mathrm{~min}$, stating that $99 \%$ of transfers are made within this period; this figure shows how diverse contexts can influence travel behavior. Similarly, all validations occurring after a time interval shorter than $3 \mathrm{~min}$ from the previous validation were considered errors and deleted. Finally, the maximum number of trips made by a user in a 24-h period was set to 6 (from $\mathrm{T}_{1}$ to $\mathrm{T}_{6}$ ), observing the distribution of trip typology (see Figure 7 in Section 3 ).

The second part of the algorithm assigns each validation to its origin and destination. By knowing the stop at which the check-in was done, the zone in which the stop is located can also be known. Three rules were adopted:

- $\quad$ the origin of each trip is always the stop in which the validation occurs; 
- the destination of each trip, excluding the last of the day, is the stop of the check-in of the following validation;

the destination of the last trip of the day is the stop of the check-in of the first validation of the next day.

Table 4. Example of the origin-destination matrix and related attributes.

\begin{tabular}{ccccc}
\hline F_ORI & F_DEST & O/D & Length $(\mathbf{m})$ & Time $(\mathbf{m i n})$ \\
\hline$\ldots$ & $\ldots$ & $\ldots$ & $\ldots$ & $\ldots$ \\
13,362 & 13,371 & $13,362-13,371$ & 2918.04 & 4.38 \\
13,362 & 23,389 & $13,362-23,389$ & 7559.56 & 11.34 \\
13,371 & 13,362 & $13,371-13,362$ & 2918.04 & 4.38 \\
13,371 & 2799 & $13,371-2799$ & $12,643.46$ & 18.97 \\
13,371 & 975 & $13,371-975$ & $14,113.34$ & 21.17 \\
13,392 & 975 & $13,392-975$ & $19,219.11$ & 28.83 \\
13,459 & 300 & $13,459-300$ & 6336.91 & 9.51 \\
13,459 & 23,559 & $13,459-23,559$ & $17,662.21$ & 26.49 \\
13,459 & 3192 & $13,459-3192$ & $13,945.47$ & 20.92 \\
13,459 & 4012 & $13,459-4012$ & $16,416.56$ & 24.62 \\
13,459 & 55,903 & $13,459-55,903$ & $35,337.86$ & 53.01 \\
$\ldots$ & $\ldots$ & $\ldots$ & $\ldots$ & $\ldots$ \\
\hline
\end{tabular}

Note: F_ORI: IDs of the origin stops; F_DEST: IDs of the destination stops.

\subsection{Definition of Transport Supply and Demand}

Transport demand refers to validation data collected over 11 weeks (22 February-8 May 2016) that allowed a database to be created with the structure shown in Table 5.

Table 5. Data characterizing the transport demand.

\begin{tabular}{cc}
\hline Variable Description & Example \\
\hline Anonymized value of Smart-card & 123456789 \\
User date of birth & 27 June 1980 \\
User age interval & 36 \\
User gender & F.ETA_3 \\
Regional code of the company on whose vehicles the validation occurs & 1 \\
Regional name of the company on whose vehicles the validation occurs & GTT \\
Registration number of the vehicle on which the validation occurs & 332 \\
Univocal code of the vehicle on which the validation occurs & 1332 \\
Number of seats of vehicle on which the validation occurs & 49 \\
Plate Number of vehicle on which the validation occurs & EP308ZC \\
Regional code of the line on which the validation occurs & $2 \mathrm{a}-1510$ \\
Extra.To code of the line on which the validation occurs & 510 \\
Extra.To code of the company supplying the line on which the validation occurs & 115 \\
Extra.To name of the company supplying the line on which the validation occurs & GTT \\
Regional code of the stop in which the validation occurs & 23693 \\
Code of the zone in which the validation occurs & 256 \\
Latitude of the stop in which the validation occurs & 44.98976101 \\
Longitude of the stop in which the validation occurs & 7.480175061 \\
Day on which the validation occurs & 11 \\
Month in which the validation occurs & 3 \\
Year in which the validation occurs & 2016 \\
Date on which the validation occurs & 11 March 2016 \\
Weekday on which the validation occurs & 5 \\
Hour in which the validation occurs & FRIDAY \\
Minute in which the validation occurs & 6 \\
Second in which the validation occurs & 36 \\
Time at which the validation occurs & 46 \\
Number of the weekday on which the validation occurs & $06: 36: 46$ \\
\hline
\end{tabular}


Table 5. Cont.

\begin{tabular}{rc}
\hline Variable Description & Example \\
\hline Time in which the validation occurs, expressed in minutes & 396 \\
Identification code of the hourly interval & 5 396 \\
Hourly interval in which the validation occurs & F.OR_LMMGV_2 \\
CALCULATION_2: First validation of the day & 5 \\
CALCULATION_1: Number of the weekday OR single daily validation & 2 \\
CALCULATION_3: Number of validations made on the same day & T1/1FRI \\
T1/1: First trip, first leg & T1/2FRI \\
T1/2: First trip, second leg & T1/3FRI \\
T1/3: First trip, third leg & T2/1FRI \\
T2/1: Second trip, first leg & T2/2FRI \\
T2/2: Second trip, second leg & T2/3FRI \\
T2/3: Second trip, third leg & T3/1FRI \\
T3/1: Third trip, first leg & T3/2FRI \\
T3/2: Third trip, second leg & T4/1FRI \\
T4/1: Fourth trip, first leg & T4/2FRI \\
T4/2: Fourth trip, second leg & T5/1FRI \\
T5/1: Fifth trip, first leg & T6/1FRI \\
T6/1: Sixth trip, first leg & S1/1FRI \\
Trip typology & 23693 \\
F_ORI: Origin stop & 13459 \\
CALCULATION_4: Destination stop excluding the last validation of the day & 13459 \\
CALCULATION_5: Destination stop of the last validation of the day & 13459 \\
Destination stop & Origin zone \\
Destination zone & 78 \\
\hline
\end{tabular}

To represent transport demand and, notably, the origin-destination matrix, a statistically representative week was individuated to better understand how the number of validations changes according to the day of the week. The representative week consists of the seven days of the week, with records for each of the number of validations closest to the average value. To estimate the average number of validations for each day of the week, outliers were removed.

Indeed, between the 22 March 2016 and 8 May 2016, some days were characterized by an anomalous number of validations. The median of the absolute deviations (MAD) from the data's median (Equation (1)) was used to detect the statistical dispersion of data and to understand if these days could be considered outliers:

$$
M A D=\operatorname{median}\left(\left|x_{j}-\operatorname{median}\left(x_{j}\right)\right|\right)
$$

where $x_{j}=$ number of validations for day $j$.

In order to use the $M A D$ as a reliable estimator for the estimation of the standard deviation, $\sigma$, (Equation (2)), one takes:

$$
\hat{\sigma}=k \cdot M A D
$$

where $k$ is equal to 1.4826 in the case of normally distributed data. Therefore, validation variables were standardised using both the classic method $(z=$ standard variable; Equation (3)) and the robust method $\left(z_{R}=\right.$ standard robust variable; Equation (4)).

$$
\begin{gathered}
z=\frac{x_{i}-\mu}{\sigma} \\
z_{R}=\frac{x_{i}-\mu}{k \cdot M A D}
\end{gathered}
$$

where $\mu=$ mean of the daily validations.

Analyzing the density distribution of the standard variables, $z_{R}$ had a larger standard deviation than $z$. Thus, it was possible to select $z_{R}=3.5$ as a threshold. According to the standard normal 
distribution tables, $z_{R}=3.5$ is equivalent to a $0.02 \%$ probability that the values assessed as outliers are included in the normal distribution.

After the $M A D$ application, outlier values were excluded and mean values were recalculated. In this manner, the representative week was defined by choosing the days where the number of validations closest to the average values were recorded.

To assess the interaction between transport supply and demand, a classification of Extra.To lines was conducted using some of the criteria suggested by Janecki \& Karon [33].

The definition of the transport supply is based on 6 criteria, as follows.

(1) The first criterion-demography—is used to classify the lines into two groups according to the population living in the municipalities served by the lines: the "main lines", crossing at least one municipality with a population between 10,000 and 20,000 inhabitants, and the "secondary lines" (the rest).

(2) The second criterion refers to the typology of the line-school lines, commuter lines, airport lines and ordinary lines-to which a specific weight is given.

(3) The third criterion is the daily average number of validations according to the percentiles of $40 \%$ and $90 \%$, split between weekdays and the weekend.

(4) The fourth criterion is related to the daily frequency of lines according to the percentiles of $40 \%$ and $90 \%$, likewise split between weekdays and the weekend.

(5) The fifth criterion is the average number of seats for every line according to the percentiles of $40 \%$ and $90 \%$.

(6) The last criterion is the ratio between the number of stops on each line and the number of lines serving each stop. For this criterion, the percentiles of $40 \%$ and $90 \%$ were again used.

\subsection{Visualization of the Transport Supply and Demand and Analysis of Their Interaction}

To represent transport supply and demand (desire lines), validation data and the timetable referring to Extra.To's buses were used. Validation data were collected and elaborated with QGis software to represent the desire lines for different days of the week and different time slots. The overlapping of Extra.To lines (as classified according to the methodology) on the desire lines allows any mismatches between transport supply and demand to be shown.

In particular, a detailed analysis was conducted on the main lines recording a low transport demand. In this case, the visualization of desire lines was based on bus-stops rather than centroids. Finally, for the main lines, the average number of validations at each bus stop was computed in order to find the most- and least-used stops.

\section{Results}

As described in Section 2, all validations that did not contain information on the bus lines were excluded from the analysis. In particular, $11 \%$ of the validations contained the error "No AVM" which means that automatic vehicle monitoring was not working at the moment of validation. Furthermore, $21 \%$ of the validations logged the error "Line ID $=0$ ", mainly due to the fact that a driver did not manually input the line ID into the on-board device.

Looking at smart-card subscriptions during the study period, users are mainly commuters, with a subscription equal to or greater than one month (56\%) (Figure 6). The users are predominantly students and women (57.1\%). 


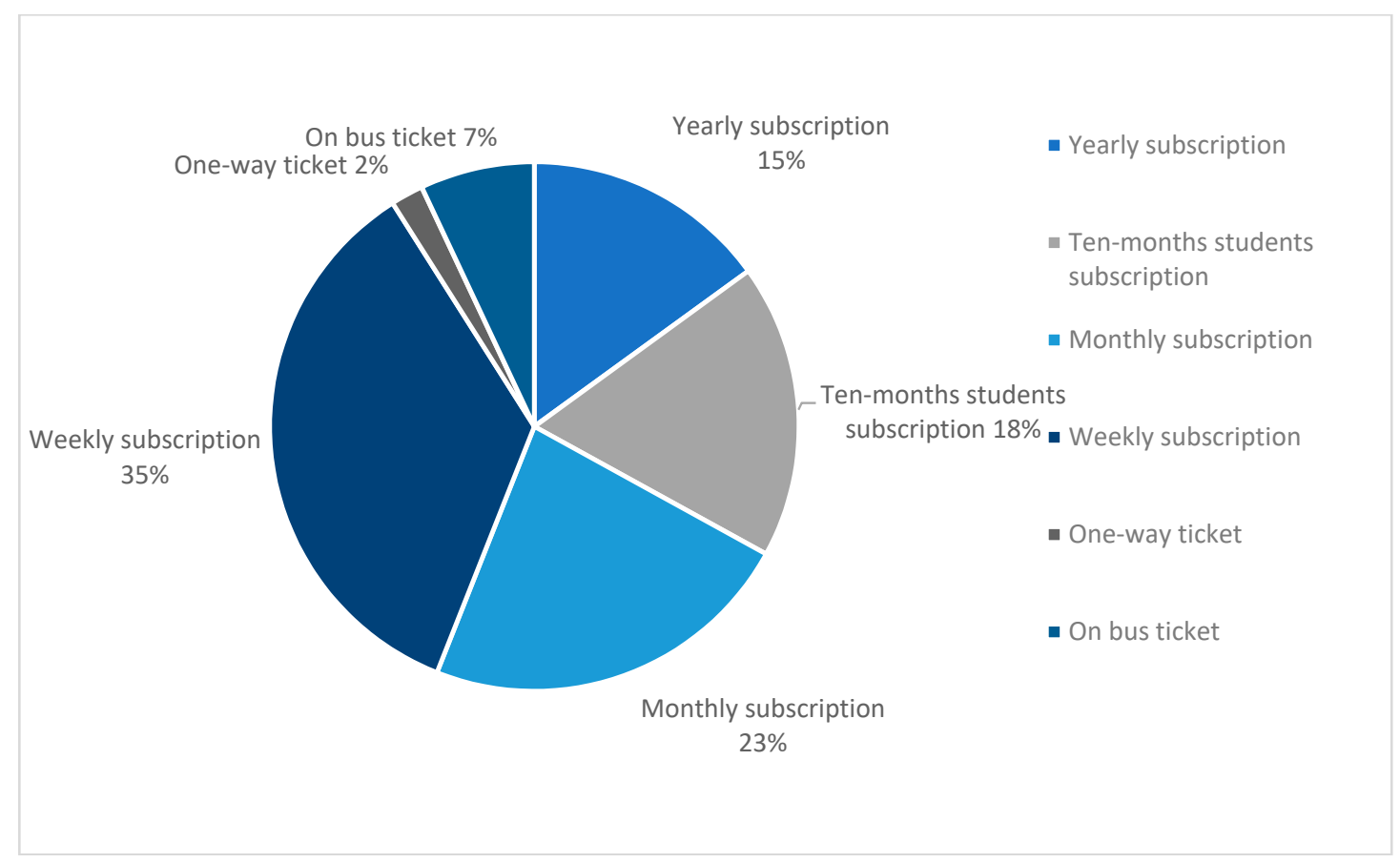

Figure 6. Percentage of subscriptions.

In Figure 7 the distribution of trip typology for one week (21-27 March 2016) is reported; only $0.51 \%$ of validations refer to the fourth, fifth and sixth trip (pie-chart on the right).

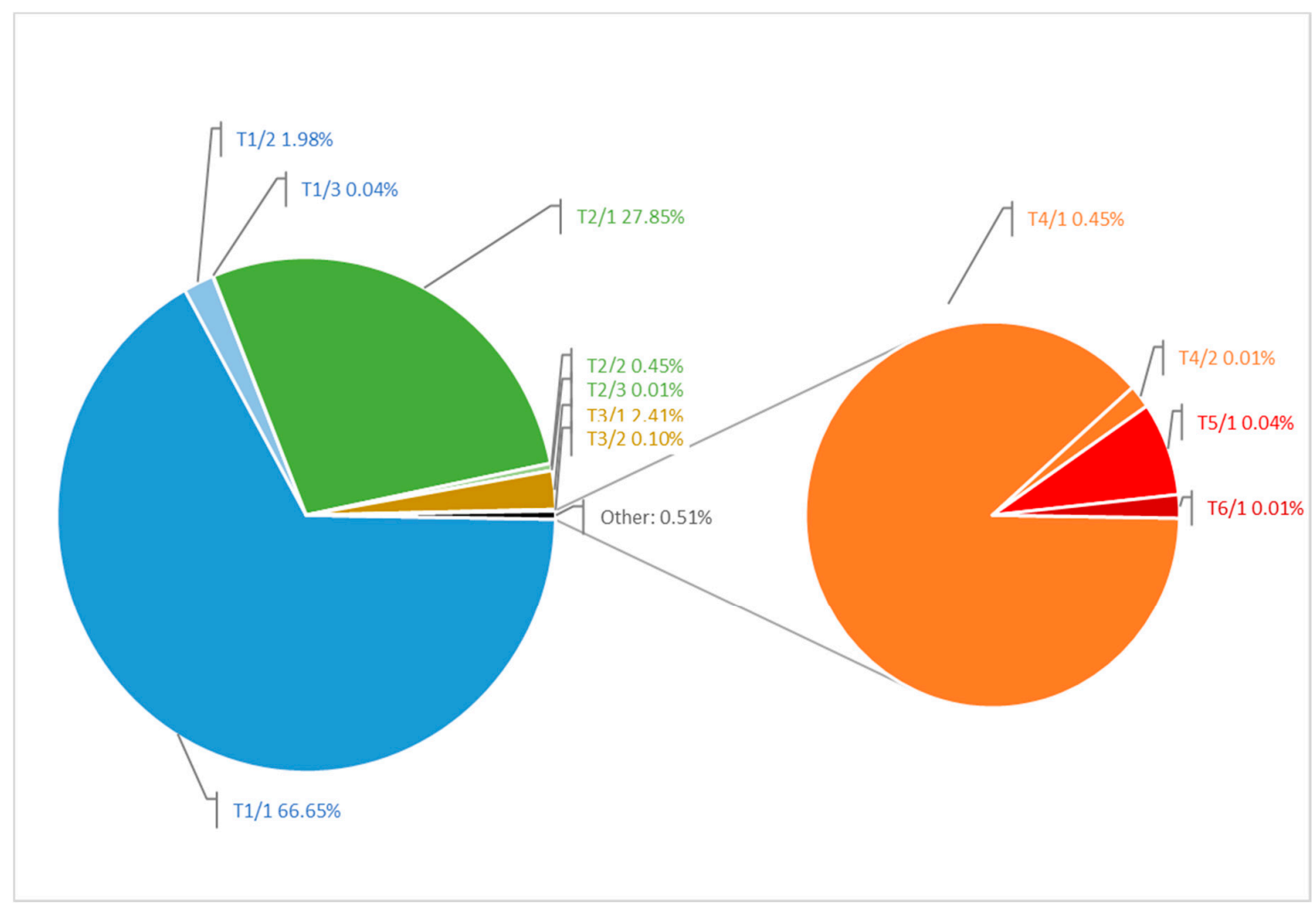

Figure 7. Trip distribution from 21 to 27 March 2016.

Analysing the distribution of the number of daily validations, peak and off-peak slots have been defined for both weekdays and weekends. In particular, as shown in Figure 8, the peaks for weekdays 
are 06:00-08:29; 13:00-14:59 and 16:00-18:59, while for weekends there are only two peaks: 6:00-08:29 and 12:00-13:59.

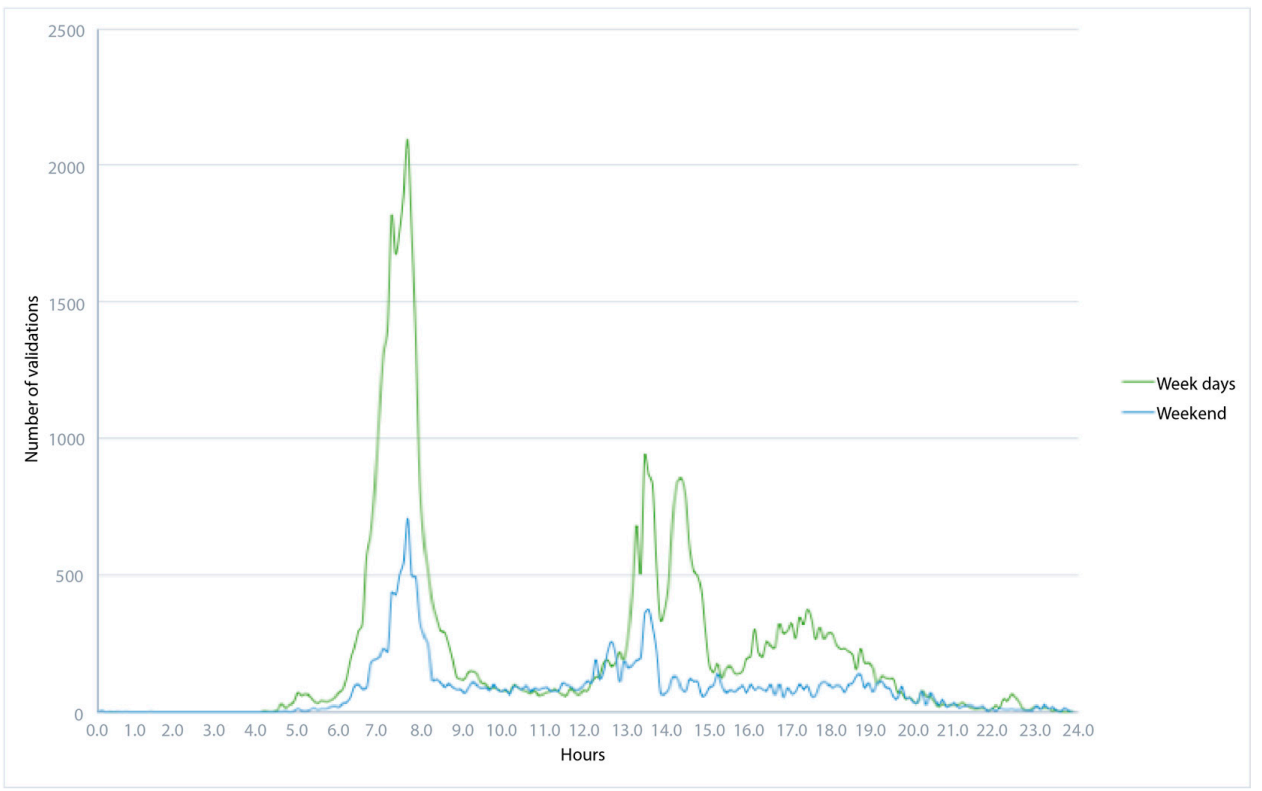

Figure 8. Distribution of validations for weekdays and weekends.

The statistically representative week defined to understand better how the number of validations changes according to the day of the week is reported in Table 6. In particular, Figure 9 shows how the average values changed after the exclusion of outlier values.

Table 6. Transport demand: representative week.

\begin{tabular}{cc}
\hline Day Name & Date \\
\hline Monday & 22 March 2016 \\
Tuesday & 12 April 2016 \\
Wednesday & 09 March 2016 \\
Thursday & 14 April 2016 \\
Friday & 06 May 2016 \\
Saturday & 23 April 2016 \\
Sunday & 24 April 2016 \\
\hline
\end{tabular}

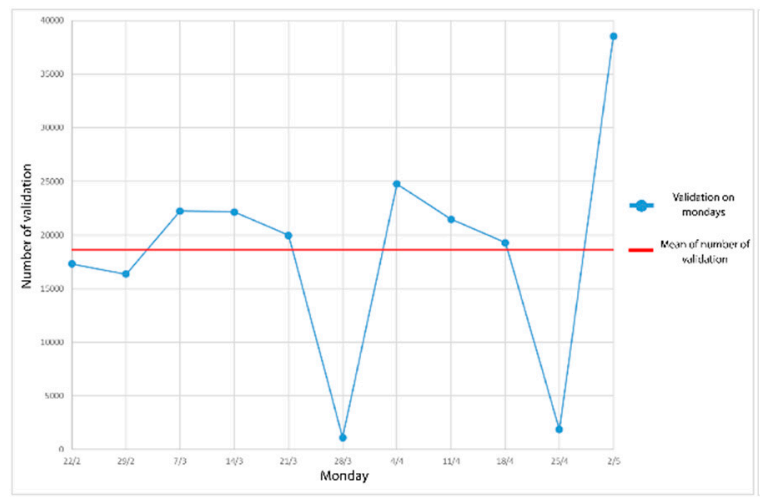

(a)

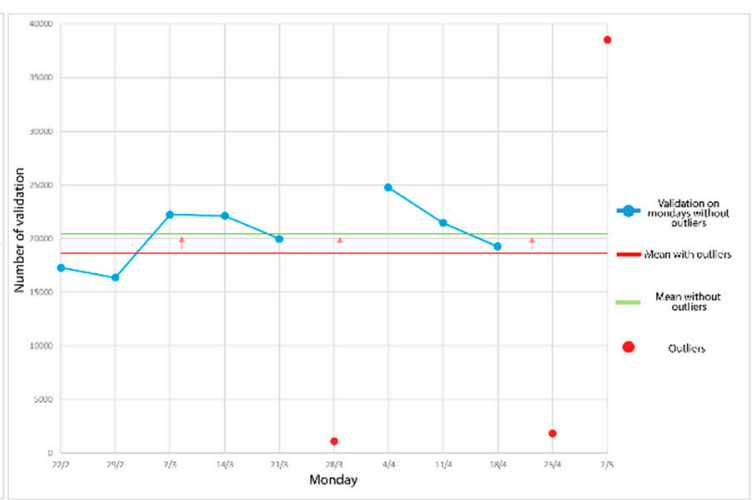

(b)

Figure 9. Distribution of validations before (a) and after (b) MAD (median of the absolute deviations) application. 
Transport Supply and Demand and Analysis of Their Interaction

According to the methodology concerning bus line classifications, three main classes were obtained. Figure 10 shows the classification of the bus lines where the "main lines" predominantly operate along the north-south axis. All cross the city of Torino.

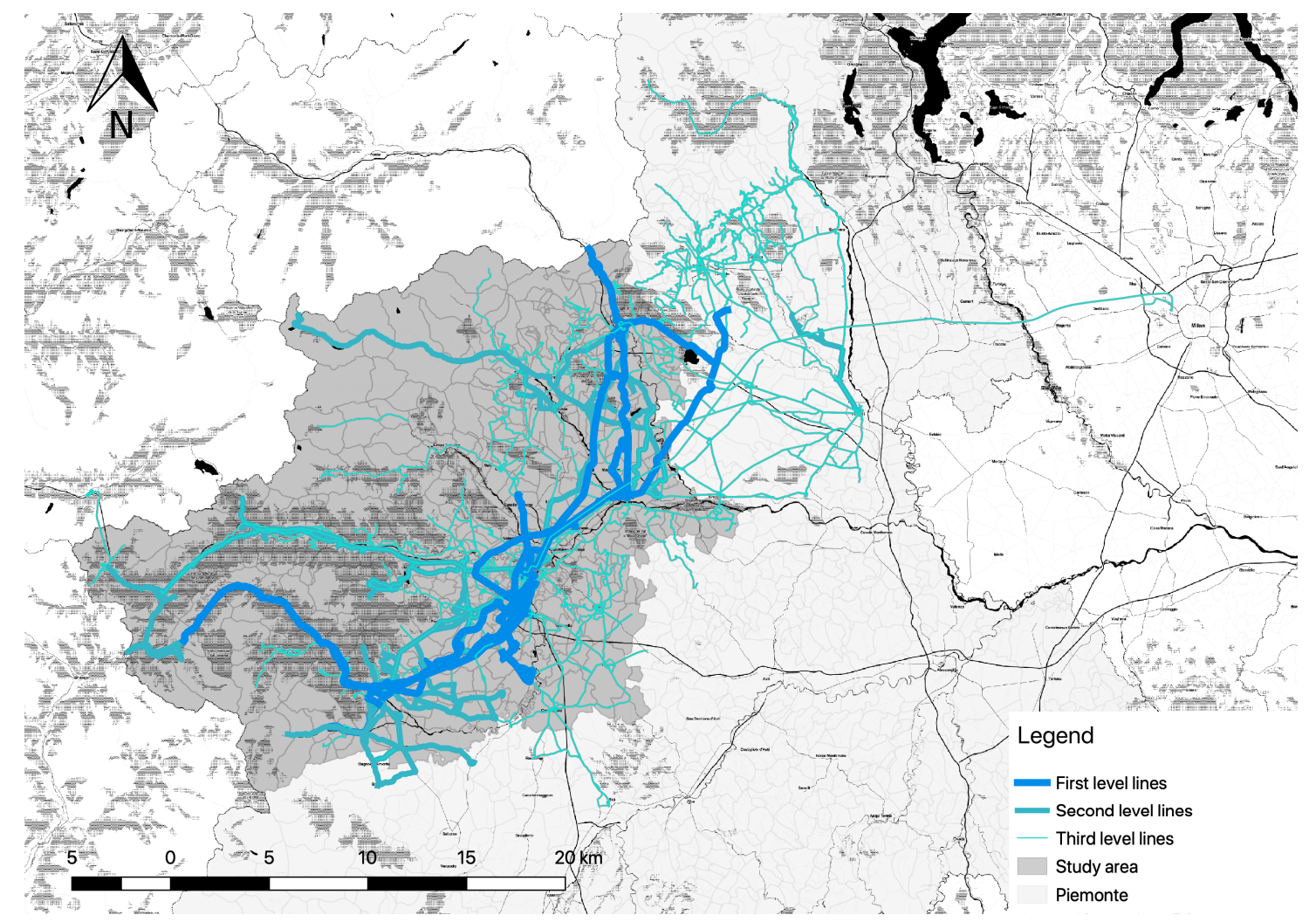

Figure 10. Extra.To line classifications.

Considering all trips during the study period, the maximum number of legs was defined for each trip. More precisely, most of the validations recorded between 22 March 2016 and 8 May 2016 were the first leg of a first trip (66.65\%), while only $27.85 \%$ were the first leg of a second trip.

Figure 11 shows the overlap between line classifications and desire lines during the representative Monday; it is possible to observe that there are some zones with "main lines" (high-level supply) but with low transport demand, notably in the west and north-east parts of the analyzed area. 


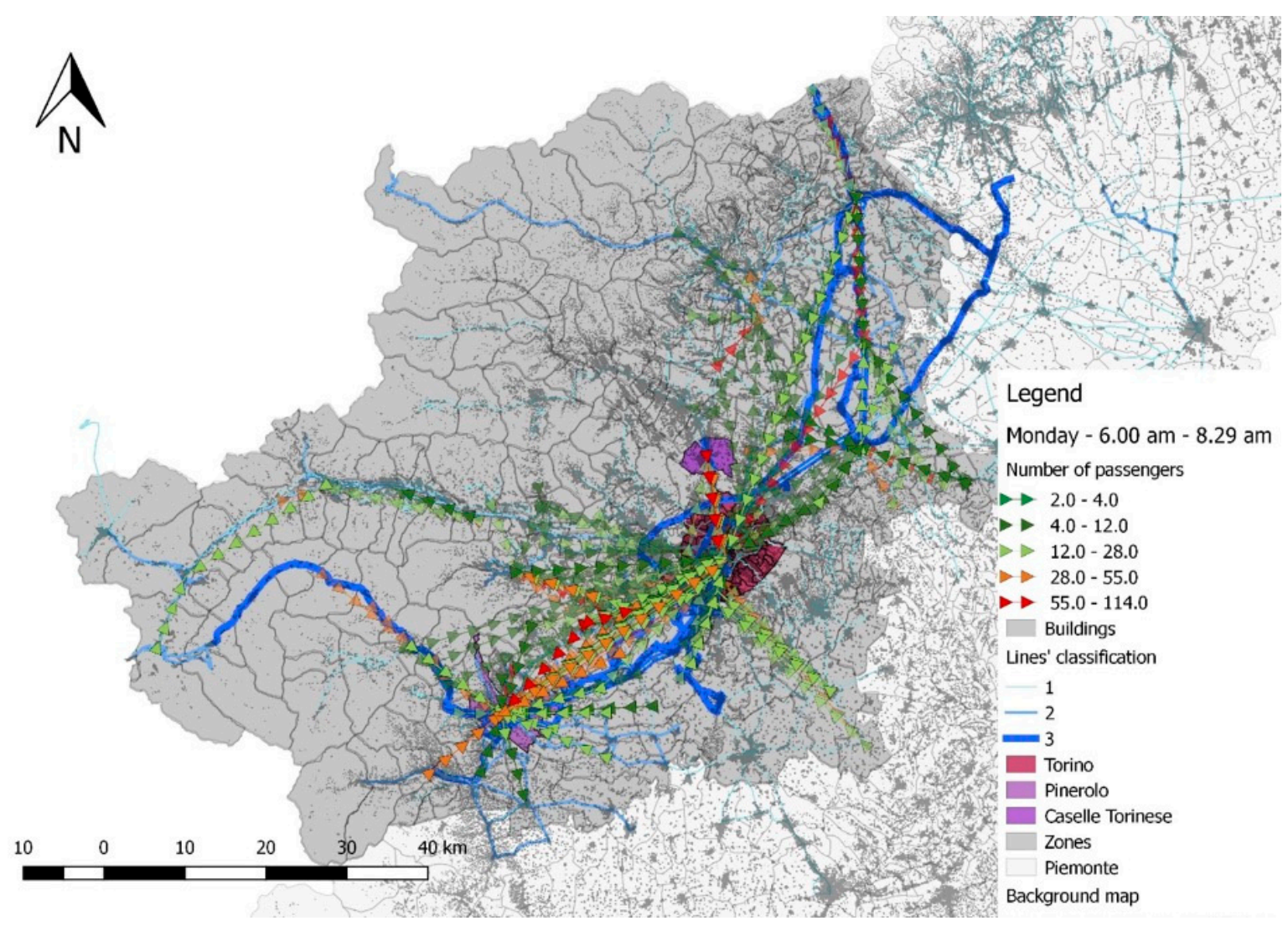

Figure 11. Overlap between line classification and desire lines.

Figure 12 shows the number of generated and attracted trips by zone during the representative Monday. The zones generating the majority of trips are Pinerolo and its surroundings (south-west) as well as Poirino and Chivasso, respectively in the south-east and north-east of Torino. Similarly, the zones attracting most trips are Pinerolo and Giaveno in the south-west, and Chivasso in the north-east.

Among the different time slots of the representative days of the week, the results show a constant high number of trips both in the south-west and in the north-west of the study area.

Therefore, a more detailed analysis was conducted in the south-west area of Torino, considering the lines connecting Torino to Pinerolo, an important hub for the province of Torino. A detailed analysis of the desire lines was carried out for provincial lines $275,282,510$, and 901 . In order to identify the most frequented stops on each line, further analysis was conducted.

Figure 13 shows a detailed analysis of desire lines on Monday, 21 March 2016; it is possible to observe during the second time range (06.00-08:29) that even though line 275 is an important provincial line, there are not many passengers who travel on the west section of this line. Indeed, Figure 13 shows that most trips go from Perosa Argentina to Pinerolo, and from Pinerolo to Torino (red arrows) which is in line with the flow of commuters from the province area.

Figure 14 shows the average number of validations (during all Mondays of the analyzed period) for each stop on line 275. The analysis highlighted that the number of validations recorded at the bus stops serving the most mountainous municipalities was low, while, on the other hand, most of the validations were recorded in Torino, at the terminus and in the municipalities close to Pinerolo. 


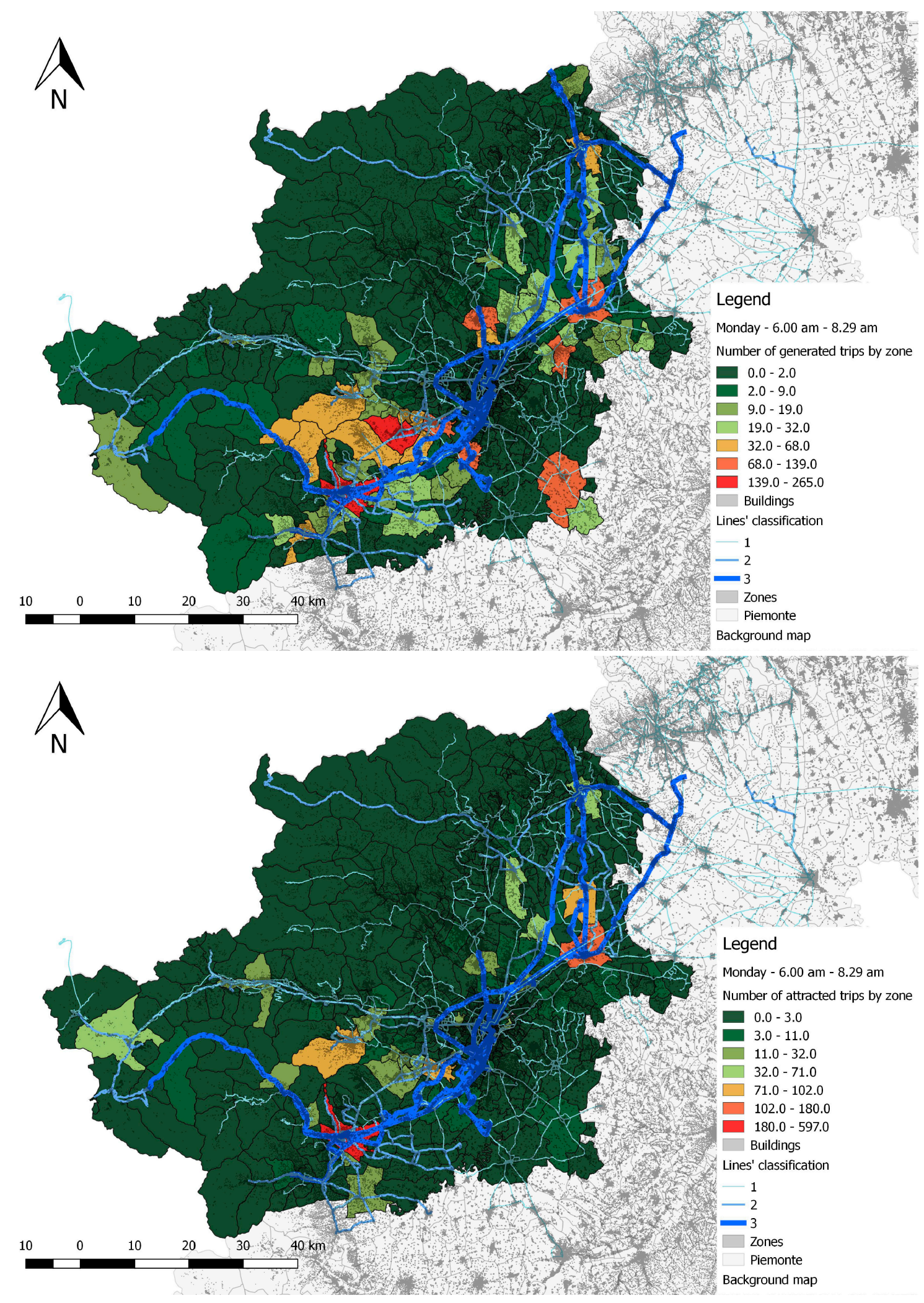

Figure 12. Number of trips generated (upper) and attracted (lower) by zones. 


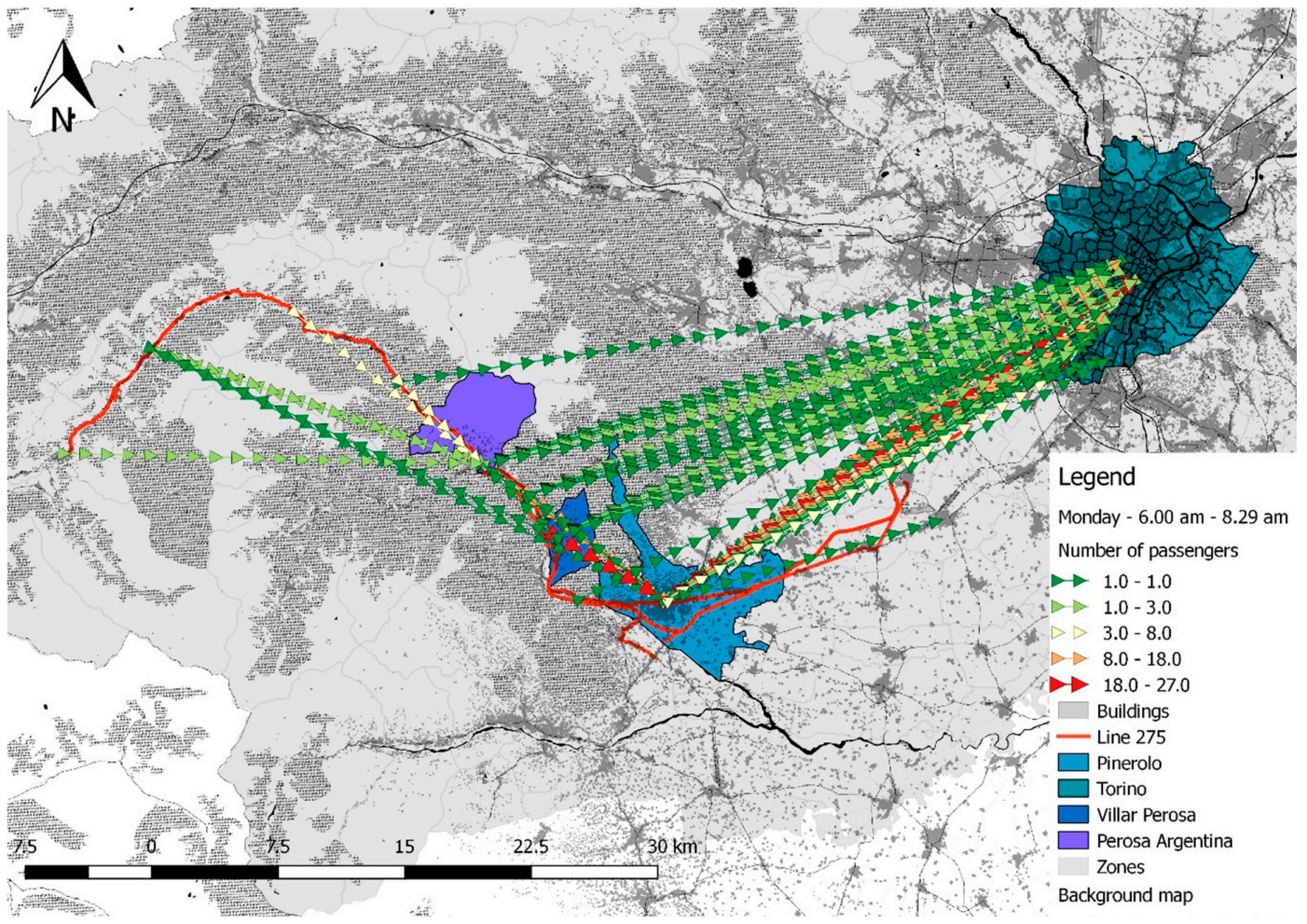

Figure 13. Line 275: detailed origin-destination analysis on Monday, time range 2.

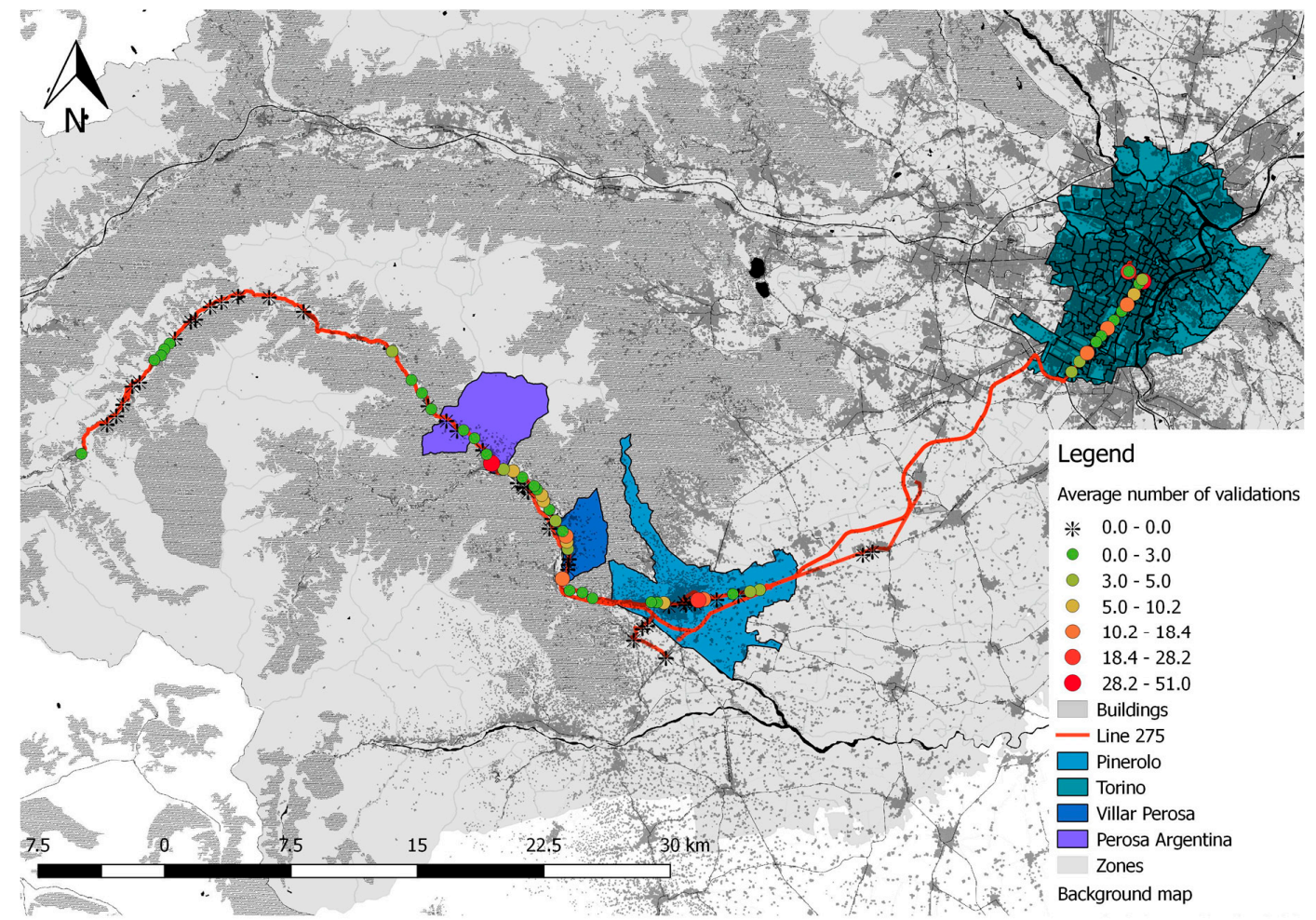

Figure 14. Average number of validations (on Monday) for each stop of line 275.

To verify the reliability of the above results, thanks to the collaboration of the transport company Extra.To, some sample measurements were carried out on the line 275 (Perosa Argentina-PineroloTorino) to verify the correctness of the model in terms of demand on the line and passengers at the bus stops (Figure 15 and Table 7). 
The measurements showed an average error of $5 \%$. This good result is also due to the fact that this line is operated by one of the two companies of the consortium with the best functioning validation system and a 100\% rate of validations. There are other rural lines, operated by small companies, with relatively poor-performing AFC systems, where the error considerably increases due to the lack of data.

\section{PASSENGERS ON BOARD [MANUAL SURVEY AND SMARTCARD DATA]}

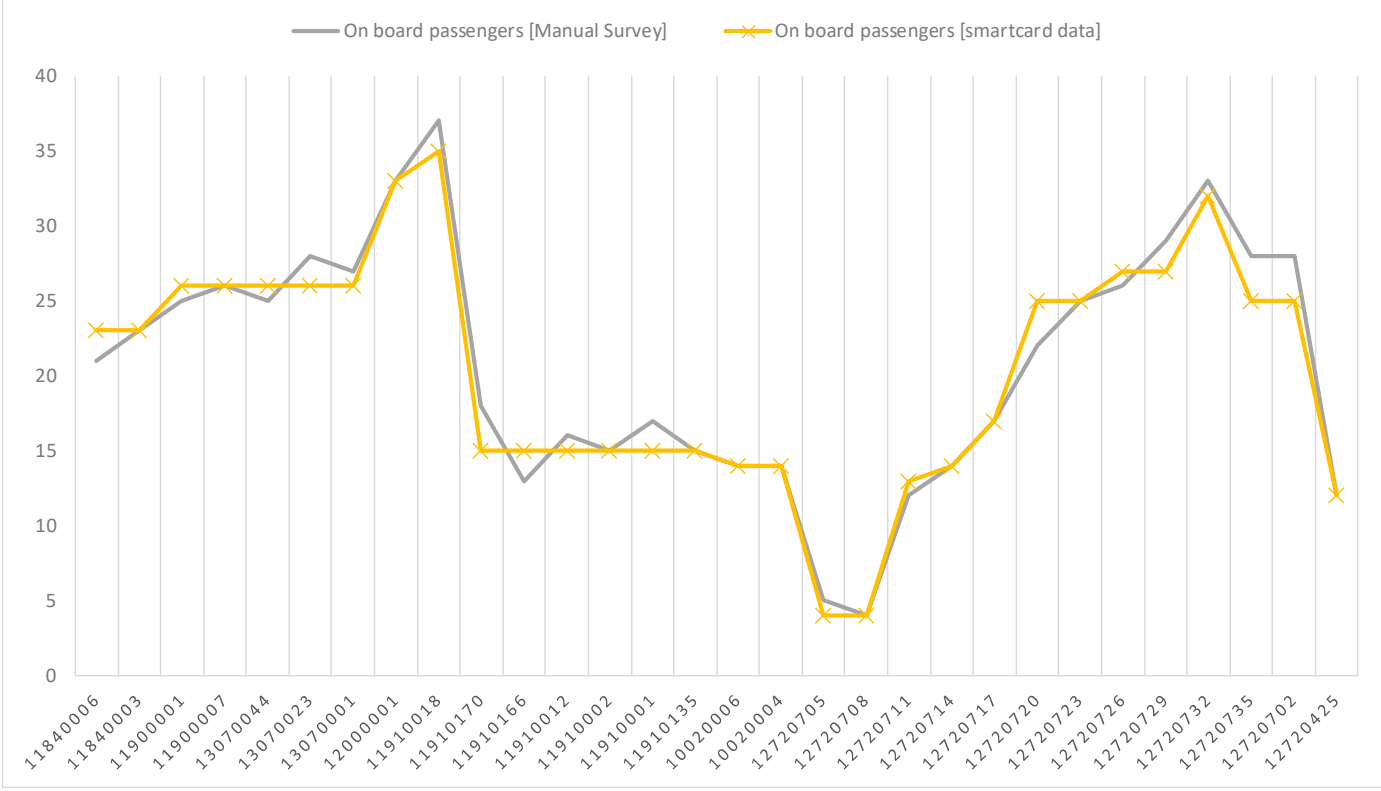

Figure 15. Number of validations (on Monday) for each stop of line 275.

Table 7. Number of validations for each stop of line 275 (manual survey and smartcard data).

\begin{tabular}{|c|c|c|c|c|c|c|c|c|c|}
\hline ID Line & $\begin{array}{c}\text { ID } \\
\text { Ride }\end{array}$ & $\begin{array}{c}\text { ID } \\
\text { Stops }\end{array}$ & $\begin{array}{c}\text { Zone } \\
\text { ID }\end{array}$ & $\begin{array}{c}\text { Arrival } \\
\text { Time } \\
\text { [hh:mm:ss] }\end{array}$ & $\begin{array}{l}\text { Alighting } \\
\text { Passengers } \\
\text { [Survey] }\end{array}$ & $\begin{array}{c}\text { Boarding } \\
\text { Passengers } \\
\text { [Survey] }\end{array}$ & $\begin{array}{c}\text { On-Board } \\
\text { Passengers } \\
\text { [Manual } \\
\text { Survey] }\end{array}$ & $\begin{array}{c}\text { On-Board } \\
\text { Passengers } \\
\text { [Smartcard } \\
\text { Data] }\end{array}$ & $\begin{array}{c}\text { Relative Error } \\
\text { of On-Board } \\
\text { Passenger (\%) }\end{array}$ \\
\hline 275 & 097A & 11840006 & 181 & 07:40:00 & 0 & 21 & 21 & 23 & 9.52 \\
\hline 275 & 097A & 11840003 & 181 & $07: 42: 00$ & 3 & 5 & 23 & 23 & 0 \\
\hline 275 & 097A & 11900001 & 187 & $07: 45: 00$ & 0 & 2 & 25 & 26 & 4 \\
\hline 275 & 097A & 11900007 & 187 & 07:47:00 & 2 & 3 & 26 & 26 & 0 \\
\hline 275 & 097A & 13070044 & 304 & 07:50:00 & 20 & 19 & 25 & 26 & 4 \\
\hline 275 & 097A & 13070023 & 304 & 07:51:00 & 2 & 5 & 28 & 26 & 7.14 \\
\hline 275 & 097A & 13070001 & 304 & 07:55:00 & 8 & 7 & 27 & 26 & 3.70 \\
\hline 275 & 097A & 12000001 & 197 & 07:58:00 & 0 & 6 & 33 & 33 & 0 \\
\hline 275 & 097A & 11910018 & 198 & 07:59:00 & 12 & 16 & 37 & 35 & 5.40 \\
\hline 275 & 097A & 11910170 & 188 & 08:00:00 & 26 & 7 & 18 & 15 & 16.66 \\
\hline 275 & 097A & 11910166 & 188 & 08:01:00 & 5 & 0 & 13 & 15 & 15.38 \\
\hline 275 & 097A & 11910012 & 188 & 08:02:00 & 8 & 11 & 16 & 15 & 6.25 \\
\hline 275 & 097A & 11910002 & 188 & 08:06:00 & 17 & 16 & 15 & 15 & 0 \\
\hline 275 & 097A & 11910001 & 188 & 08:07:00 & 0 & 2 & 17 & 15 & 11.76 \\
\hline 275 & 097A & 11910135 & 188 & 08:10:00 & 15 & 13 & 15 & 15 & 0 \\
\hline 275 & 097A & 10020006 & 778 & $08: 26: 00$ & 1 & 0 & 14 & 14 & 0 \\
\hline 275 & 097A & 10020004 & 778 & 08:28:00 & 0 & 0 & 14 & 14 & 0 \\
\hline 275 & 097A & 12720705 & 169 & 08:51:00 & 12 & 3 & 5 & 4 & 0,2 \\
\hline 275 & 097A & 12720708 & 162 & 08:55:00 & 3 & 2 & 4 & 4 & 0 \\
\hline 275 & 097A & 12720711 & 154 & 08:59:00 & 2 & 10 & 12 & 13 & 8.33 \\
\hline 275 & 097A & 12720714 & 156 & 09:03:00 & 0 & 2 & 14 & 14 & 0 \\
\hline 275 & 097A & 12720717 & 142 & 09:07:00 & 1 & 4 & 17 & 17 & 0 \\
\hline 275 & 097A & 12720720 & 128 & 09:11:00 & 3 & 8 & 22 & 25 & 13.63 \\
\hline 275 & 097A & 12720723 & 128 & 09:16:00 & 0 & 3 & 25 & 25 & 0 \\
\hline 275 & 097A & 12720726 & 109 & 09:19:00 & 4 & 5 & 26 & 27 & 3.84 \\
\hline 275 & 097A & 12720729 & 109 & 09:23:00 & 6 & 9 & 29 & 27 & 6.89 \\
\hline 275 & 097A & 12720732 & 111 & 09:26:00 & 1 & 5 & 33 & 32 & 3.03 \\
\hline 275 & 097A & 12720735 & 113 & 09:29:00 & 5 & 0 & 28 & 25 & 10.71 \\
\hline 275 & 097A & 12720702 & 113 & 09:33:00 & 2 & 2 & 28 & 25 & 10.71 \\
\hline 275 & 097A & 12720425 & 82 & 09:37:00 & 16 & 0 & 12 & 12 & 0 \\
\hline
\end{tabular}




\section{Discussion and Conclusions}

This research proposes a method to analyze smart-card validations in urban, suburban and rural areas to better understand how transport demand matches existing supply, most particularly of bus services. Arguably, mining smart-card validations can facilitate data collection traditionally carried out through surveys or travel diaries.

Even though many studies of AFC systems and origin-destination estimation have been carried out [25-27], a detailed analysis on large areas (provinces) is something new. In fact, our area covers more than $6000 \mathrm{~km}^{2}$ while Gswchwender et al. [25] and Seaborn et al. [27] focused on areas of about $650 \mathrm{~km}^{2}$ and $1500 \mathrm{~km}^{2}$, respectively in Santiago, Chile, and London, England.

However, like several studies in the literature, this research is also affected by a lack of validation of the model, since entry-exit data are not available. As Tian et al. [24] explain, only half of the studies examined validate the models, even though sample data sources and sizes are quite diverse. In our case, the agreement made with Extra.To has proven to be essential to the collection of validation data over several months; other case studies collected validation data for only a few weeks. This longer duration allowed us to obtain a relatively large sample $(1,500,000$ validations) and to analyze recurrent patterns of users that allowed us to verify the correctness of the hypotheses. Furthermore, sample measurements have allowed us to check the reliability of the results, at least on a few lines, showing that the hypotheses made were close to real user behavior and that the algorithm performed sufficiently well.

Detailed analyses of flows and desire lines can be conducted according to the day of the week and time slot. In particular, more detailed analysis related to travel behavior can be carried out by considering the age-range of users or by analyzing socio-economic information through questionnaires and/or focus groups. This approach, however, is becoming more and more challenging due to the recent DGPR (also known as Directive 95/46/EC), the EU Data Protection Directive to protect the privacy of, and all personal data collected for or about, citizens of the EU; this especially relates to processing, using or exchanging such data. In the case where ID cards have to be continuously changed (as already occurs in France), analysis of recurrent patterns will not be possible, and additional work will be needed to try to individuate recurrent patterns.

Nevertheless, transport authorities can easily apply this methodology for several purposes:

- $\quad$ redesigning public transport lines and bus services according to passenger flows, together with data related to latent demand;

- improving the quality of infrastructure at stops-namely, bus-shelters or screens to display real-time information - using the information related to the number of users boarding at each stop;

- $\quad$ individuating potentially redundant stops and, thus, increasing average travel speed, as stops are eliminated due to lack (or low number) of boarding/alighting passengers.

Arguably, the overlap between the classification of bus lines and passenger flows highlighted the fact that some of the main lines do not carry an adequate number of passengers. In addition, the detailed analysis that focused on line number 275 identified a number of stops where no validations were recorded. This result can be important to alert public transport companies and transport authorities, calling for a further analysis of the overall transport demand (served by all modes). If there is a transport demand served by modes other than public transport, this may imply that the service is not offered in accordance with user needs and should be reorganized to attract more customers. Furthermore, transport operators could assess passenger flows and the most frequented bus stops to identify the most profitable lines and bus services, and eventually provide demand responsive transport (DRT) for those areas characterized by low transport demand. As suggested by Ma et al. [26], investing in direct bus services in areas with higher transport demand can influence user behavior and reduce car congestion.

Much research has already focused on the estimation of origin-destination matrices in wide urban areas and megacities such as Beijing, Santiago, London, Istanbul, etc. $[8,25,26]$. This paper has tried to 
go further, however, focusing on an uneven study area, both from the point of view of geographical features and local topography, and population density. Indeed, such heterogeneity was borne out by the classification of lines. In this regard, the methodology used for comparing transport demand and supply, as well as for representing the desire lines, can also fit other contexts well, including at smaller geographical scales, and help to understand how to improve existing bus services.

Methodologically, our approach does not substantially differ from previous studies aimed at inferring the destination from boarding-entry data $[8,16]$. Our data-collection method, however, allows a far more fine-grained temporal analysis than Barry et al. [16], where limitations of the validation system imposed a precision of $\pm 3 \mathrm{~min}$ on transaction times. Whereas Zhao et al. [8] focused on the study of personal mobility patterns, using a similar methodology, our scope was to set up a tool for transport planners that can directly feed existing transport models with our aggregated origin-destination matrix. Finally, a cross-model combining our trip-chaining algorithm with a table of effective bus rides would allow us to improve the spatial-temporal analysis of traveler's mobility patterns.

Our research is now continuing with the analysis of latent demand, using the most recent regional survey carried out by the transport authority in 2013, and thanks to a new survey launched at the end of 2017 (data analysis is ongoing). The goal is to understand mobility patterns (all modes) in greater detail and improve the estimation of origin-destination matrices from smart-cards, adding new variables related to socio-demographic characteristics, travel times and distances, etc., to, finally, put forward more innovative policies and solutions.

Besides the enrichment of the model with additional variables, our current effort is devoted to model validation. In the Oise department (Hauts-de-France region, north of France) data collection from smart-cards is ongoing, and the model developed to date will be validated using a two-fold approach. These data come from two sources: (a) APC systems installed on a few buses to check the number of passengers on board; and (b) equipment developed by us to count passengers through the detection of mobile devices. Furthermore, the refined model will be tested again in the Piedmont region on some bus lines in the Cuneo province (southern part of Piedmont) where, in the last month, a test has been ongoing, and passengers have been validating both boarding and alighting.

All these initiatives are supported by the local authorities (municipalities, provinces, transport authorities and transport operators) due to their need to know the number of customers using public transport and desire to provide an attractive public transport service able to trigger a significant modal shift, as expected by most Sustainable Urban Mobility Plans (SUMPs). In fact, continuous budgetary cuts to public transport require a new approach towards mobility, in which it should be considered a service and, hence, tailored to user needs, taking into account the ever-scarcer resources devoted to funding public transport.

Author Contributions: This study is a joint work of the three authors. C.P. and D.L., conceived while all three authors (C.P., D.L. and J.-B.G.) defined the approach to use and the methodology to follow. D.L. carried out a first brief literature search and wrote a first short scheme. C.P. revised the first draft, made additional literature searches, re-wrote, and added parts/sections. C.P. made the final revision. All three authors read and approved the final manuscript.

Funding: This research received no external funding.

Acknowledgments: This paper is a result of a collaboration between Politecnico di Torino and Extra.To company, which made their validation data available for analysis.

Conflicts of Interest: The authors declare no conflict of interest.

\section{References}

1. Pelletier, M.-P.; Trépanier, M.; Morency, C. Smart Card data use in public transit: A literature review. Transp. Res. Part C 2011, 19, 557-568. [CrossRef]

2. Shelfer, M.; Procaccino, J. Smart Card Evolution. Commun. ACM 2002, 45, 83-88. [CrossRef] 
3. Mayes, K.; Markantonakis, K.; Hancke, G. Transport ticketing security and fraud controls. Inf. Secur. Tech. Rep. 2009, 14, 87-95. [CrossRef]

4. Robinson, S.; Narayanan, B.; Toh, N.; Pereira, F. Methods for pre-processing smartcard data to improve data quality. Transp. Res. Part C 2014, 49, 45-58. [CrossRef]

5. Lovric, M.; Li, T.; Vervest, P. Sustainable revenue management: A smart card enabled agent-based modeling approach. Decis. Support Syst. 2013, 54, 1587-1601. [CrossRef]

6. Ma, X. Smart Card Data Mining and Inference for Transit System Optimization and Performance Improvement. Ph.D. Thesis, University of Washington, Seattle, WA, USA, 2013.

7. Kieu, L.M.; Bhaskar, A.; Chung, E. A Modified Density-based Scanning Algorithm with Noise for Spatial Travel Pattern Analysis from Smart Card AFC Data. Transp. Res. Part C Emerg. Technol. 2015, 58, 193-207. [CrossRef]

8. Zhao, J.; Qu, Q.; Zhang, F.; Xu, C.; Liu, S. Spatio-temporal Analysis of Passenger Travel Patterns in Massive Smart Card Data. IEEE Trans. Intell. Transp. Syst. 2017, 18, 3135-3146. [CrossRef]

9. Bagchi, M.; White, P.R. What Role for Smart-card Data from Bus Systems? Munic. Eng. 2004, 157, 39-46. [CrossRef]

10. Bagchi, M.; White, P.R. The Potential of Public Transport Smart Card Data. Transp. Policy 2005, 12, 464-474. [CrossRef]

11. Zhang, F.; Yuan, N.J.; Wang, Y.; Xie, X. Reconstructing Individual Mobility from Smart Card Transactions: A Collaborative Space Alignment Approach. Knowl. Inf. Syst. 2015, 44, 299-323. [CrossRef]

12. Kusakabe, T.; Asakura, Y. Behavioural data mining of transit smart card data: A data fusion approach. Transp. Res. Part C 2014, 45, 179-181. [CrossRef]

13. Spurr, T.; Chu, A.; Chapleau, R.; Piché, D. A smart card transaction "travel diary" to assess the accuracy of the Montréal household travel survey. Transp. Res. Procedia 2015, 11, 350-364. [CrossRef]

14. Agard, B.; Morency, C.; Trépanier, M. Mining Public Transport User Behaviour from Smart Card Data. IFAC Proc. Vol. 2006, 39, 399-404. [CrossRef]

15. Han, G.; Sohn, K. Activity Imputation for Trip-chains Elicited From Smart-card Data Using a Continuous. Hidden Markov Model. Transp. Res. Part B 2016, 83, 121-135. [CrossRef]

16. Barry, J.J.; Newhouser, R.; Rahbee, A.; Sayeda, S. Origin and Destination Estimation in New York City with Automated Fare System Data. Transp. Res. Rec. J. Transp. Res. Board 2002, 1817, 183-187. [CrossRef]

17. Munizaga, M.A.; Palma, C. Estimation of a Disaggregate Multimodal Public Transport Origin-Destination Matrix from Passive Smartcard Data from Santiago, Chile. Transp. Res. Part C Emerg. Technol. 2012, 24, 9-18. [CrossRef]

18. Yu, C.; He, Z.C. Analysing the Spatial-temporal Characteristics of Bus Travel Demand Using the Heat Map. J. Transp. Geogr. 2017, 58, 247-255. [CrossRef]

19. Trepanier, M.; Chapleau, R. Destination estimation from public transport smartcard data. IFAC Proc. Vol. 2006, 39, 393-398. [CrossRef]

20. Li, D.; Lin, Y.; Zhao, X.; Song, H.; Zou, N. Estimating a transit passenger trip origin-destination matrix using automatic fare collection system. In Proceedings of the International Conference on Database Systems for Advanced Applications, Hong Kong, China, 22-25 April 2011; Springer: Berlin/Heidelberg, Germany, 2011; pp. 502-513.

21. Munizaga, M.; Devillaine, F.; Navarrete, C.; Silva, D. Validating Travel Behavior Estimated from Smartcard Data. Transp. Res. Part C Emerg. Technol. 2014, 44, 70-79. [CrossRef]

22. Jung, J.; Sohn, K. Deep-learning Architecture to Forecast Destinations of Bus Passengers from Entry-only Smart-card Data. IET Intell. Transp. Syst. 2017, 11, 334-339. [CrossRef]

23. Alsger, A.; Assemi, B.; Mesbah, M.; Ferreira, L. Validating and Improving Public Transport Origin-Destination Estimation Algorithm Using Smart Card Fare Data. Transp. Res. Part C Emerg. Technol. 2016, 68, 490-506. [CrossRef]

24. Tian, L.; Dazhi, S.; Peng, J.; Kaixi, Y. Smart Card Data Mining of Public Transport Destination: A Literature Review. Information 2018, 9, 18. [CrossRef]

25. Gschwender, A.; Munizaga, M.; Simonetti, C. Using smart card and GPS data for policy and planning: The case of Transantiago. Res. Transp. Econ. 2016, 242-249. [CrossRef]

26. Ma, X.; Liub, C.; Wen, H.; Wang, Y.; Wu, Y.-J. Understanding commuting patterns using transit smart card data. J. Transp. Geogr. 2016, 58, 135-145. [CrossRef] 
27. Seaborn, C.; Attanucci, J.; Wilson, N.H.M. Using Smart Card Fare Payment Data to Analyse multimodal public transport journeys in London. Transp. Res. Rec. 2009, 55-62. [CrossRef]

28. Bip Piemonte. Available online: http:/ / bip.piemonte.it/ (accessed on 19 July 2018).

29. Agenzia Mobilità Piemontese. Indagine Sulla Mobilità Delle Persone e Sulla Qualità dei Trasporti Rapporto Sulla Regione Piemonte. Torino, Italy, 2016. Available online: http://mtm.torino.it/it/dati-statistiche/ indagini (accessed on 19 July 2018).

30. SAP-Business Object. Available online: www.sap.com/products/bi-platform.html (accessed on 19 July 2018).

31. Decreto Legislativo 30 Giugno 2003, n. 196. Codice in Materia di Protezione dei Dati Personali. Gazzetta Ufficiale n. 174 of 29 July 2003-Supplemento Ordinario n. 123. Available online: http:/ / www.gazzettaufficiale. it/atto/serie_generale/caricaDettaglioAtto / originario?atto.dataPubblicazioneGazzetta=2003-07-29\&atto. codiceRedazionale=003G0218 (accessed on 23 September 2018).

32. Environmental Systems Research Institute (ESRI). ArcGIS Network Analyst; Environmental Systems Research Institute: Redlands, CA, USA, 2011; Available online: https:/ /www.esri.com/en-us/arcgis/products/arcgisnetwork-analyst/overview (accessed on 19 July 2018).

33. Janecki, R.; Karon, G. The Method of Hierarchization of Public Transport Lines and Evaluation of Their Adaptation to the Users Needs. In Proceedings of the 13th Scientific and Technical Conference Transport Systems, Theory and Practice, Katowice, Poland, 19-21 September 2016; pp. 15-25.

(C) 2018 by the authors. Licensee MDPI, Basel, Switzerland. This article is an open access article distributed under the terms and conditions of the Creative Commons Attribution (CC BY) license (http://creativecommons.org/licenses/by/4.0/). 